\title{
Nuclear and cytoplasmic localization of interferon- $\tau$ in in vitro-produced bovine blastocysts
}

\author{
Kelly M. JohnSON ${ }^{\mathrm{a}}$, Xavier AlvAREz ${ }^{\mathrm{b}}$, Olga N. BORKHSENIOUS ${ }^{\mathrm{c}}$, \\ H. Michael KUBISCH ${ }^{\text {a* }}$ \\ ${ }^{a}$ Division of Veterinary Medicine, Tulane National Primate Research Center, \\ Covington, LA 70433, USA \\ b Division of Comparative Pathology, Tulane National Primate Research Center, Covington, \\ LA 70433, USA \\ ${ }^{c}$ School of Veterinary Medicine, Louisiana State University, Baton Rouge LA 70803, USA
}

(Received 21 March 2005; accepted 18 April 2005)

\begin{abstract}
Experiments were conducted to detect interferon- $\tau$ in bovine in vitro-derived blastocysts by transmission electron (TEM) and confocal microscopy. TEM showed the presence of IFN- $\tau$ in the cytoplasm and the nuclei of expanded blastocysts. Confocal microscopy similarly confirmed the presence of IFN- $\tau$ in the trophectoderm of blastocysts. The distribution of IFN- $\tau$ appeared variable with some cells showing strong labeling while others appeared to be devoid of the protein.
\end{abstract}

interferon- $\tau$ / embryo / blastocyst / gene expression / IVF

\section{INTRODUCTION}

Interferon-tau (IFN- $\tau$ ) is a protein secreted by ruminant embryos that is thought to be the primary signal for the establishment and maintenance of pregnancy. It is a type I interferon that has evolved approximately 36 MYA from an IFN- $\omega$ by acquisition of a promoter region that imparted trophectoderm-specific expression [1]. IFN- $\tau$ can be readily detected by its antiviral activity in the culture medium of in vivo- and in vitroderived bovine blastocysts [2-4]. Moreover, IFN- $\tau$ gene transcription as well as secretion of protein have been shown to be affected by a number of genetic and environmental factors [5-11]. Previous reports have demonstrated the presence of IFN- $\tau$ protein as well as mRNA in the trophecto- derm of ovine and bovine conceptuses that were obtained from pregnant animals [1214]. However, nothing is known about the cellular distribution of IFN- $\tau$ during preelongation stages of development. The objective of this study, therefore, was to use transmission electron and confocal microscopy to localize IFN- $\tau$ in in vitro-derived bovine blastocysts.

\section{MATERIALS AND METHODS}

\subsection{Embryo production}

Oocytes from abattoir-source ovaries were matured in vitro in M199 medium supplemented with $10 \%$ defined fetal calf serum, with the addition of $2 \mu \mathrm{g} \cdot \mathrm{mL}^{-1}$-estradiol-17 $\beta$

\footnotetext{
* Corresponding author: mkubisch@tulane.edu
} 

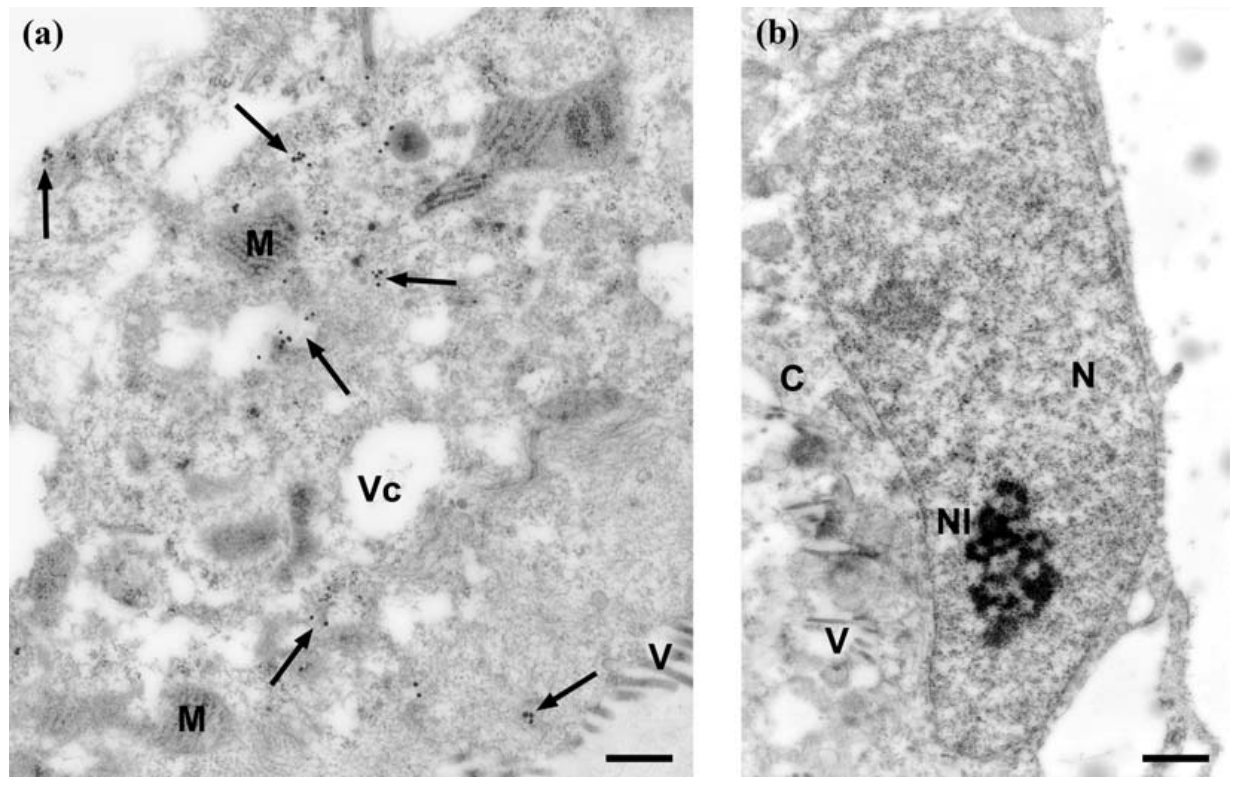

Figure 1. Transmission electron microscopy image of trophectoderm cell cytoplasm. Positive image (a), negative control in which primary antibody was omitted (b). Positive signals are indicated by arrows. Vc vacuole, $\mathrm{V}$ villi, $\mathrm{M}$ mitochondrion, $\mathrm{N}$ nucleus, $\mathrm{C}$ cytoplasm, NI nucleolus. Bar: $0.5 \mu \mathrm{m}$.

and $2 \mu \mathrm{g} \cdot \mathrm{mL}^{-1} \mathrm{FSH}$ in $5 \% \mathrm{CO}_{2}$ at $38.5^{\circ} \mathrm{C}$ for $24 \mathrm{~h}$. Mature oocytes were fertilized, and the presumptive zygotes were then cultured in CR1aa medium with $5 \%$ defined FCS (Hyclone, Logan UT) in $5 \% \mathrm{CO}_{2}$ at $38.5^{\circ} \mathrm{C}$. The embryos remained in culture for 7 days.

\subsection{Preparation of embryos for electron microscopy}

Blastocysts were embedded in $2 \%$ agarose (low melting agar) and excess agarose was trimmed off. Agarose blocks were fixed in $0.5 \%$ glutaraldehyde $+2 \%$ formaldehyde in $0.1 \mathrm{M} \mathrm{NaCaC}$ buffer, $\mathrm{pH}$ 7.3. After dehydration in a series of ethanol dilutions, the cubes were embedded in $100 \%$ London Resin White acrylic resin (Polysciences, Warrington, PA) and polymerized overnight at $68^{\circ} \mathrm{C}$. Thin sectioning $(80 \mathrm{~nm})$ was performed by an MT- XL ultratome (RMC,
Tucson, AZ) and sections were mounted on collodion (2\%)-coated nickel grids.

To block non-specific binding, sections were treated with $25 \%$ nonfat milk, for $6 \mathrm{~h}$ in a refrigerator at $4{ }^{\circ} \mathrm{C}$. The grids were incubated for $2 \mathrm{~h}$ with a polyclonal primary antibody GTP1 (diluted 1:10) raised against a recombinant IFN- $\tau$ (a gift of Dr. Mike Roberts, University of Missouri, USA). This antibody has been shown to be specific to IFN- $\tau$ [15]. Incubation was followed by exposure to a secondary Goatanti-rabbit (EMS, Hatfield, PA, USA) coupled to $15 \mathrm{~nm}$ of colloidal gold (1:10) for $1.5 \mathrm{~h}$ at RT. The specificity of immunolabeling was evaluated by comparing labeled profiles generated with primary antibody and normal rabbit serum at the same dilution. Sections were stained in 5\% uranyl acetate, then with CNA lead. Thin sections were examined by TEM using a Zeiss 10 (Zeiss, Germany). 

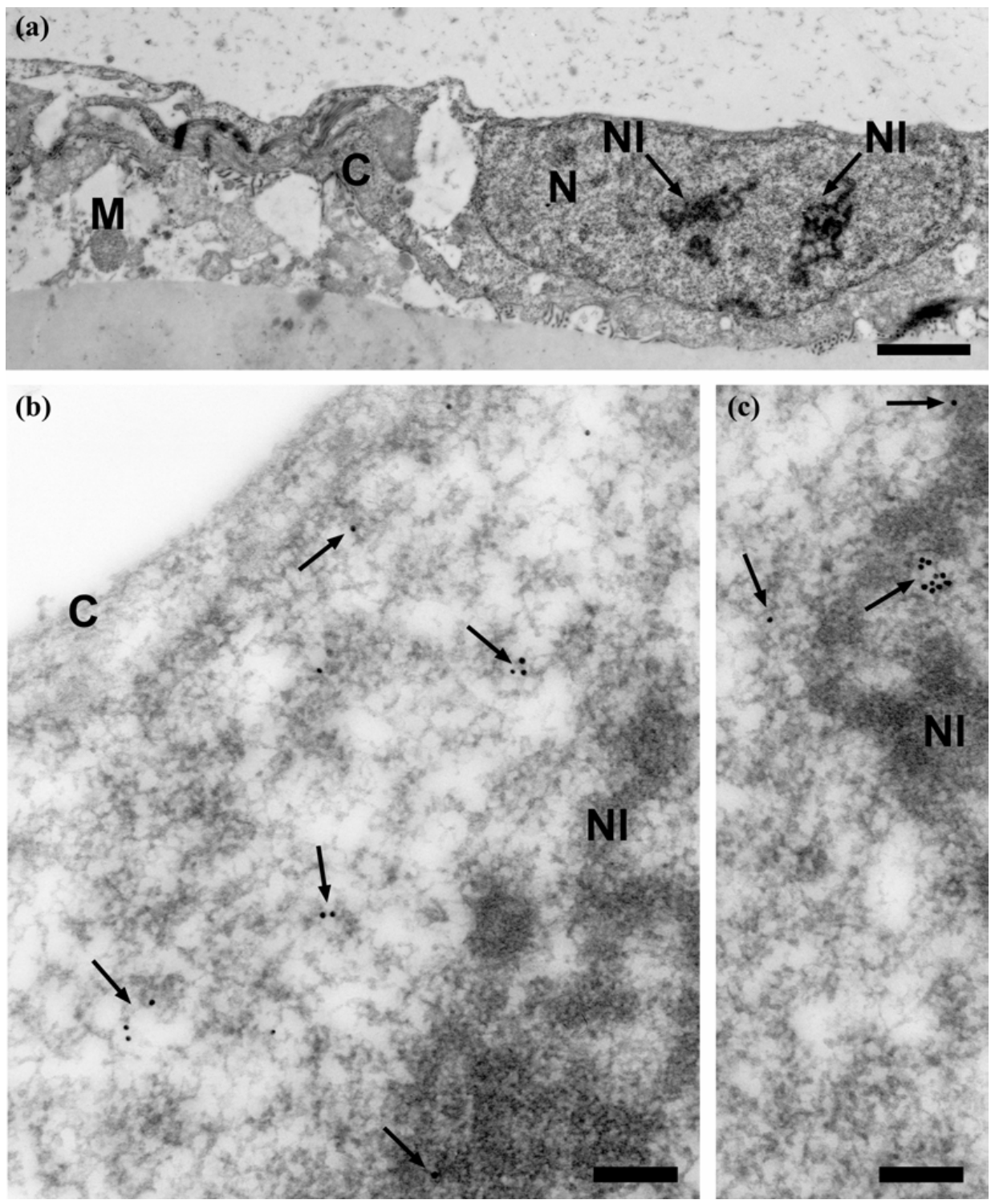

Figure 2. Transmission electron microscopy image of trophectoderm blastomere nucleus (a) and magnification of nucleolar regions (b and $\mathbf{c}$ ). Positive signals are indicated by arrows. $\mathrm{N}$ nucleus, NI nucleoli, M mitochondrion, C cytoplasm. Bars: $2.0 \mu \mathrm{m}(\mathbf{a}) ; 0.2 \mu \mathrm{m}(\mathbf{b}, \mathbf{c})$.

\subsection{Preparation of embryos for confocal microscopy}

Embryos were fixed in fresh $2 \%$ paraformaldehyde for $20 \mathrm{~min}$ and incubated in PBS with $0.2 \%$ Fish Skin Gelatin (Sigma Chemical, St. Louis, MO, USA) and $0.1 \%$ Triton X-100 (Sigma Chemical, St. Louis, MO, USA) for $20 \mathrm{~min}$ at r.t. This was followed by incubation in $10 \%$ goat serum for $30 \mathrm{~min}$ 


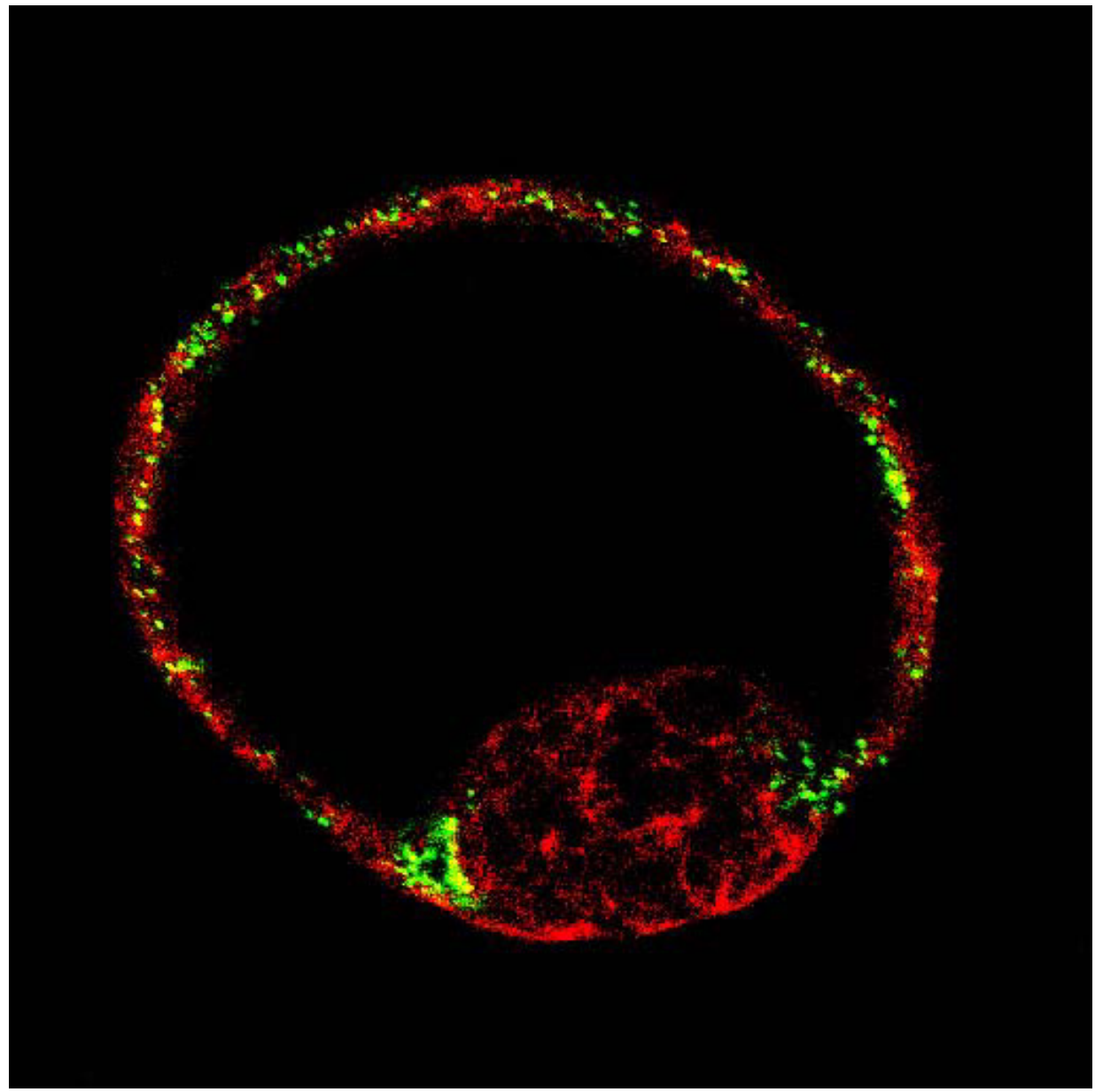

Figure 3. Confocal microscope image of a cross-sectioned non-hatched day 7 blastocyst stained for IFN- $\tau$ (green) and actin (red). The image shows the trophectoderm with positive staining for IFN- $\tau$ and the ICM on the lower right.

and incubation in Endogenous BiotinBlocking Kit (Molecular Probes, Eugene, OR, USA) to reduce background. The embryos were then incubated for $30 \mathrm{~min}$ at r.t. in $10 \%$ NSS containing the IFN- $\tau$ antibody at 1:500 dilution. Embryos were washed twice in the PBS/FSG/T $\times 100$, and incubated in a biotin X100-labeled goat anti-rabbit IgG secondary antibody (Molecular Probes, Eugene, OR, USA) at 1:1000 in $10 \%$ NSS for $45 \mathrm{~min}$ at room temperature. The embryos were washed twice before incubation in streptavidin AlexaFluor 488 (Molecular Probes, Eugene, OR, USA) at $1: 1000$ in $\mathrm{PBS} / \mathrm{FSG} / \mathrm{T} \times 100$ for $10 \mathrm{~min}$. The embryos were washed again in PBS/FSG/ $\mathrm{T} \times 100$, and then stained for actin with phalloidin AlexaFluor 568 at 1:50 dilution in $10 \%$ NSS. The embryos were washed a second time in $\mathrm{PBS} / \mathrm{FSG} / \mathrm{T} \times 100$ and then 


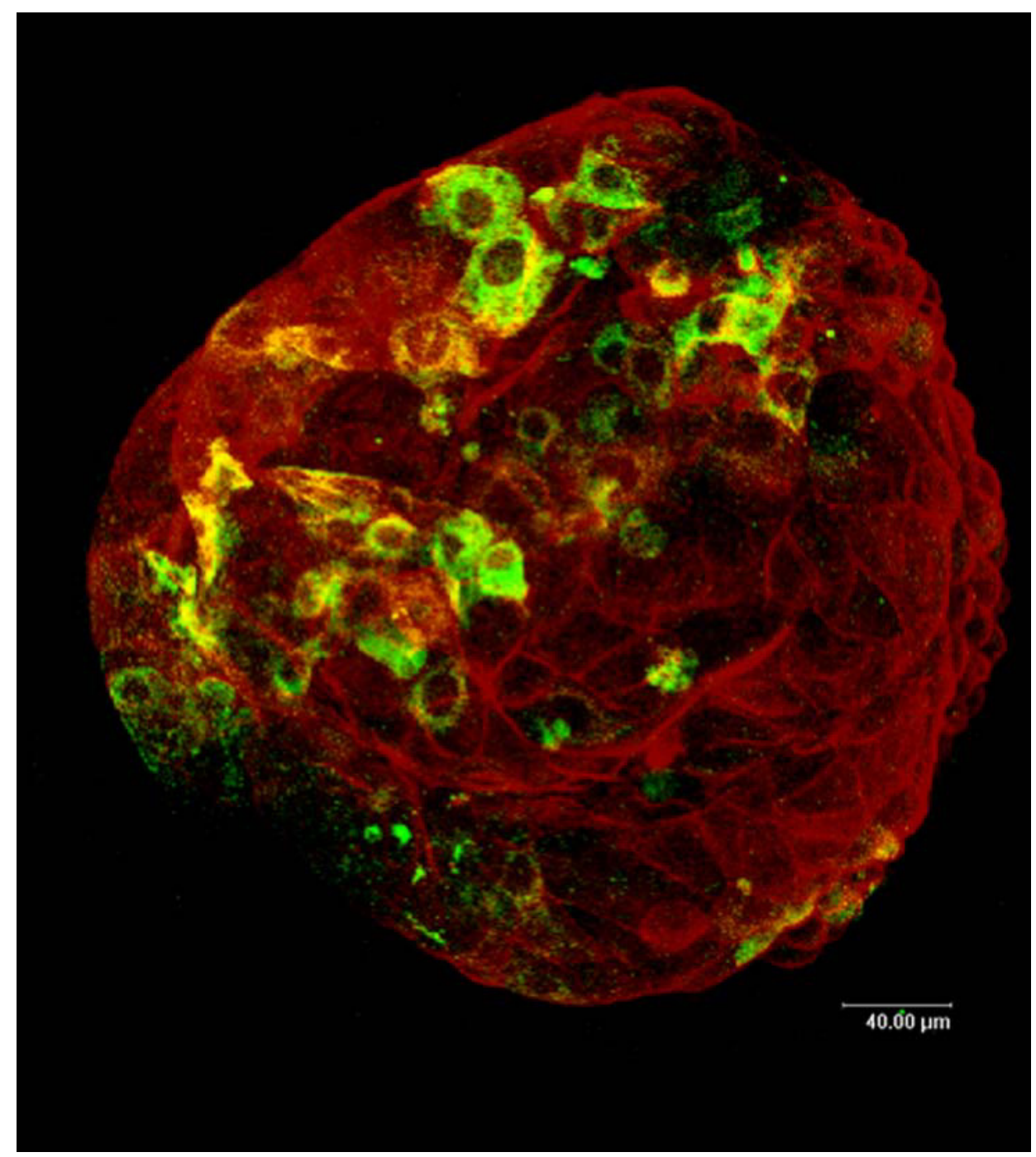

Figure 4. Confocal microscope image of a hatched blastocyst, stained for IFN- $\tau$ (green) and actin (red). The ICM can be seen on the lower left.

mounted on slides with a glycerol and DABCO anti-quenching mounting medium (non-hatched embryos) or PBS/FSG/T×100 (hatched embryos). The embryos were imaged on a Leica Systems laser-scanning confocal microscope with Image-Pro software (Leica Microsystems, Heidelberg, Germany).

\section{RESULTS}

\subsection{Electron microscopy}

A total of nine blastocysts were analyzed by electron microscopy each involving the examination of several cells. Analysis with gold-labeled antibody against the primary 
IFN- $\tau$ antibody revealed interferon particles in the cytoplasm of all sections that were examined (Fig. 1a), while omission of the primary antibody and incubation with rabbit sera did not produce any positive labeling in any of the sections (Fig. 1b). Signals appeared to be clustered although this could not be correlated with any cellular structures. What proved most surprising was the observation that IFN- $\tau$ was also seen in the nuclei of trophectodermal cells in hatched blastocysts, often in close proximity to the nucleolar region (Fig. 2a-2c). In several nuclei, the same positive signals could be detected in consecutive sections, precluding the likelihood that these were artifacts.

\subsection{Confocal microscopy}

IFN- $\tau$ was found in the trophectoderm of all blastocysts that were examined. Crosssectioning showed IFN- $\tau$ to be restricted to the trophectoderm (Fig. 3). IFN- $\tau$ seemed to be concentrated in higher levels adjacent to the border with the inner cell mass. Analysis of whole blastocysts revealed that the expression was not evenly distributed throughout the trophectoderm, with protein detectable to varying degrees in individual cells (Fig. 4). The control embryos in which the primary antibody had been omitted did not show any positive signals (data not shown).

\section{DISCUSSION}

The data presented here extend previous findings that IFN- $\tau$ is a protein that is produced solely by the trophectoderm of the cattle conceptus since we did not detect any positive signals in the ICM. A striking observation in the present study is the large variation in the amount of IFN- $\tau$ that is seen between individual cells. The transcription factor Oct-4 has been shown to be one of the factors required to maintain a non-differentiated cellular state $[16,17]$. Work by Ezashi et al. [18] has demonstrated that Oct-4 is capable of silencing IFN- $\tau$ expression by forming a complex with Ets- 2 and one of the early events in the formation of the trophectoderm is a down regulation of Oct-4. Analysis of Oct-4 expression has revealed a strikingly similar variability within the trophectoderm [19]. It is conceivable that this could, in turn, account for the high variability of IFN- $\tau$ seen in this study.

One of the intriguing outcomes of the present study is that IFN- $\tau$ was detected in the nuclei of trophoblast cells. Since the same signals could often be found in consecutive sections of the same nucleus the possibility of an artifact can be safely precluded. IFN- $\tau$ has been shown to induce expression of a number of genes in endometrial cells and it appears to mediate this through signal transduction pathways such as STAT 1 and 2 [20]. Translocation of IFN- $\tau$ into the nucleus, however, would obviously point to the possible existence of other mechanisms of action.

How IFN- $\tau$ is translocated into the nucleus is unclear, although it does contain a putative nuclear localization sequence (NLS) at the C-terminus that consists of a KRLRK motif. This KRLRK motif is found in all bovine, deer and bison IFN- $\tau$ and, in a slightly changed form, in musk ox, goat and sheep. The bovine motif is homologous to what has been described as the center of nine variant nuclear localization sequences all of which contain the tetrameric consensus $(R / K) \times(R / K)[21,22]$. This motif appears in this configuration or in slight variations in a number of proteins that are known to be translocated into the nucleus [23-26]. Moreover, and this is of particular interest, this NLS motif is also found in Tyk2 and JAK-1, two components of the Type 1 IFN signal transduction pathway $[27,28]$.

It is noteworthy that translocation into the nucleus has been demonstrated for another interferon, namely IFN- $\gamma$. Its translocation appears to involve the formation of a complex of IFN- $\gamma$ with the interferon- $\gamma$ receptor subunit 1 (IFNGR1) and the transcription 
factor STAT1 $\alpha$. IFN- $\gamma$ has a nuclear localization sequence at its $C$ terminus, which appears to facilitate nuclear translocation by binding to the nuclear importer nucleoprotein interactor 1 (NPI-1) $[29,30]$. There is evidence that activated STAT $1 \alpha$ fails to undergo nuclear translocation in the absence of the IFN- $\gamma$ nuclear localization sequence [31]. Moreover, more recent evidence has shown that an IFN- $\gamma$ mimetic containing the C-terminal residues of the mouse IFN- $\gamma$ including the NLS was able to act as a chaperone and facilitate nuclear translocation of STAT $1 \alpha$ [32].

It is at present not possible to dismiss the possibility that nuclear translocation might be an artifact of in vitro culture, particularly in light of an earlier study of in vivo-derived sheep conceptuses that failed to note nuclear localization [14]. However, that study was performed on conceptuses at much later stages of development and this discrepancy might simply reflect developmentally regulated changes in IFN- $\tau$ activities. Conversely our findings may point towards an as yet unknown function of IFN- $\tau$ in embryonic development.

\section{ACKNOWLEDGMENTS}

The authors wish to thank Dr. Mike Roberts for the IFN- $\tau$ antibody and Josh Welferd for assistance in preparations of images. This research was supported by a grant (HMK) from the National Institutes of Health (HD 36421).

\section{REFERENCES}

[1] Roberts RM, Ezashi T, Rosenfeld CS, Ealy AD, Kubisch HM. Evolution of the interferon- $\tau$ genes and their promoters, and maternal-trophoblast interactions in control of their expression. Reproduction Suppl 2003, 61: 239-251.

[2] Hernandez-Ledezma JJ, Sikes JD, Murphy CN, Watson AJ, Schultz GA, Roberts RM. Expression of bovine trophoblast interferon in conceptuses derived by in vitro techniques. Biol Reprod 1992, 47: 374-380.
[3] Kubisch HM, Larson MA, Ealy AD, Murphy $\mathrm{CN}$, Roberts RM. Genetic and environmental determinants of interferon- $\tau$ secretion by in vivo- and in vitro-derived bovine blastocysts. Anim Reprod Sci 2001, 66: 1-13.

[4] Stojkovic M, Buttner M, Zakhartchenko V, Riedl J, Reichenbach HD, Wenigerkind H, Brem G, Wolf E. Secretion of interferon-tau by bovine embryos in long-term culture: comparison of in vivo derived, in vitro produced, nuclear transfer and demi-embryos. Anim Reprod Sci 1999, 55: 151-162.

[5] Kubisch HM, Larson MA, Roberts RM. Relationship between age at blastocyst formation and interferon- $\tau$ secretion by in vitro-derived bovine embryos. Mol Reprod Dev 1998, 49: 254-260.

[6] Larson MA, Kubisch HM. The effects of group size on development and interferon- $\tau$ secretion by in vitro fertilized and cultured bovine blastocysts. Hum Reprod 1999, 14: 2075-2079.

[7] Kubisch HM, Larson MA, Kiesling DO. Control of interferon- $\tau$ secretion by in vitroderived bovine blastocysts during extended culture and outgrowth formation. Mol Reprod Dev 2001, 58: 390-397.

[8] Larson MA, Kimura K, Kubisch HM, Roberts RM. Sexual dimorphism among bovine embryos in their ability to make the transition to expanded blastocyst and in the expression of the signaling molecule IFN- $\tau$. Proc Natl Acad Sci USA 2001, 98: 9677-9682.

[9] Kimura K, Spate LD, Green MP, Murphy CN, Seidel GE Jr, Roberts RM. Sexual dimorphism in interferon-tau production by in vivoderived bovine embryos. Mol Reprod Dev 2004, 67: 193-199.

[10] Wrenzycki C, Herrmann D, Keskintepe L, Martins A, Sirisathien S, Brackett B, Niemann $\mathrm{H}$. Effects of culture system and protein supplementation on mRNA expression in preimplantation bovine embryos. Hum Reprod 2001, 16: 893-901.

[11] Lonergan P, Rizos D, Gutierrez-Adan A, Moreira PM, Pintado B, de la Fuente J, Boland MP. Temporal divergence in the pattern of messenger RNA expression in bovine embryos cultured from the zygote to blastocyst stage in vitro or in vivo. Biol Reprod 2003, 69: 1424-1431.

[12] Farin CE, Imakawa K, Roberts RM. In situ localization of mRNA for the interferon, ovine trophoblast protein-1, during early embryonic development of the sheep. Mol Endocrinol 1989, 3: 1099-1107.

[13] Farin CE, Imakawa K, Hansen TR, McDonnell JJ, Murphy CN, Farin PW, Roberts RM. Expression of trophoblastic interferon genes 
in sheep and cattle. Biol Reprod 1990, 43: 210-218.

[14] Wooding FB, Morgan G, Roberts RM. Quantitative immunogold ultracryomicrotome studies of the distribution of periimplantation proteins in the sheep. Cell Tissue Res 1991, 265: 83-93.

[15] Talbot NC, Caperna TJ, Edwards JL, Garrett W, Wells KD, Ealy AD. Bovine blastocystderived trophectoderm and endoderm cell cultures: interferon tau and transferrin expression as respective in vitro markers. Biol Reprod 2000, 62: 235-247.

[16] Pesce M, Anastassiadis K, Schöler HR. Oct4: lessons of totipotency from embryonic stem cells. Cells Tissues Organs 1999, 165: 144152.

[17] Pesce M, Schöler HR. Oct-4: control of totipotency and germline determination. Mol Reprod Dev. 2000, 55: 452-457.

[18] Ezashi T, Roberts RM. Regulation of interferon- $\tau$ gene promoters by growth factors that target the Ets-2 composite enhancer: A possible model for maternal control of IFN- $\tau$ production by the conceptus during early pregnancy. Endocrinology 2004, 145: 4452-4460.

[19] Roberts RM, Ezashi T, Das P. Trophoblast gene expression: transcription factors in the specification of early trophoblast. Reprod Biol Endocrinol 2004, 2: 47.

[20] Stewart DM, Johnson GA, Vyhlidal CA, Burghardt RC, Safe SH, Yu-Lee LY, Bazer FW, Spencer TE. Interferon-tau activates multiple signal transducer and activator of transcription proteins and has complex effects on interferon-responsive gene transcription in ovine endometrial epithelial cells. Endocrinology 2001, 142: 98-107.

[21] Kalderon D, Roberts BL, Richardson WD, Smith AE. A short amino acid sequence able to specify nuclear location. Cell 1984, 39: 499-509.

[22] LaCasse EC, Lefebvre YA. Nuclear localization signals overlap DNA- or RNA-binding domains in nucleic acid-binding proteins. Nucl Acids Res. 1995, 23: 1647-1656.

[23] Kume S, Muto A, Aruga J, Nakagawa T, Michikawa T, Furuichi T, Nakade S, Okano
H, Mikoshiba K. The Xenopus IP3 receptor: structure, function, and localization in oocytes and eggs. Cell 1993, 73: 555-570.

[24] Kadonaga JT, Carner KR, Masiarz FR, Tjian $\mathrm{R}$. Isolation of cDNA encoding transcription factor Sp1 and functional analysis of the DNA binding domain. Cell 1987, 51: 1079-1090.

[25] Tsuchiya E, Uno M, Kiguchi A, Masuoka K, Kanemori Y, Okabe S, Mikayawa T. The Saccharomyces cerevisiae NPS1 gene, a novel CDC gene which encodes a $160 \mathrm{kDa}$ nuclear protein involved in $\mathrm{G} 2$ phase control. EMBO J 1992, 11: 4017-4026.

[26] Green S, Walter P, Kumar V, Krust A, Bornert JM, Argos P, Chambon P. Human oestrogen receptor cDNA: sequence, expression and homology to v-erb-A. Nature 1986, 320: 134139.

[27] Wilks AF Two putative protein-tyrosine kinases identified by application of the polymerase chain reaction. Proc Natl Acad Sci USA 1989, 86: 1603-1607.

[28] Velazquez L, Fellous M, Stark GR, Pellegrini $\mathrm{S}$. A protein tyrosine kinase in the interferon alpha/beta signaling pathway. Cell 1992, 70: 313-322.

[29] Subramaniam PS, Larkin J 3rd, Mujtaba MG, Walter MR, Johnson HM. The COOH-terminal nuclear localization sequence of interferon gamma regulates STAT1 alpha nuclear translocation at an intracellular site. J Cell Sci 2000, 113: 2771-2781.

[30] Subramaniam PS, Johnson HM. Lipid microdomains are required sites for the selective endocytosis and nuclear translocation of IFNgamma, its receptor chain IFN-gamma receptor-1, and the phosphorylation and nuclear translocation of STAT1 $\alpha$. J Immunol 2002, 169: 1959-1969.

[31] Ahmed CM, Burkhart MA, Mujtaba MG, Subramaniam P, Johnson HM. The role of IFNgamma nuclear localization sequence in intracellular function. J Cell Sci 2003, 116: 3089-3098.

[32] Subramaniam PS, Flowers LO, Haider SM, Johnson HM. Signal transduction mechanism of a peptide mimetic of interferon-gamma. Biochemistry 2004, 43: 5445-5454. 